\title{
DRIVING ForCes OF INTERNATIONAL PHARMACEUTICAL FIRMS' FDI INTO CHINA
}

\author{
Fuming Jiang \\ The Australian National University \\ Canberra, Australia
}

\begin{abstract}
This paper presents the results of an exploratory investigation into the factors that drove the international pharmaceutical firms to make foreign direct investment (FDI) into the Chinese pharmaceutical manufacturing industry during the period from 1980 to 1998. Research results show that international pharmaceutical firms' FDI into China was predominantly motivated by China's specific location factors. China's market size, with its great potential, played the most important role. The factors of rapid economic development and growth, China's open-door policy, and relatively stable political conditions were also found to be important factors. The incentive policies provided by China had limited impact on pharmaceutical firms FDI decisions. The results suggest that FDI decisions of early entrants who started FDI before 1992 were more likely to consider the open-door policy as the second most important factor, whereas late entrants whose FDI started since 1992 seemed more likely to consider the Chinese economic development and growth as the second most important factor. The results also suggest that relatively stable political conditions in China have had a stronger positive influence on the FDI decisions of the late entrants. Low labor and establishment costs in China as well as cultural related factors were not found to be significant factors for international pharmaceutical investors.
\end{abstract}

\section{Introduction}

China has attracted substantial foreign direct investment (FDI) since the passage of the Chinese-Foreign equity joint venture law by the National People's Congress of China in 1979. As shown in Figure 1, the growth trends of FDI have undergone two major phases. During the period of 1979-1991, the FDI flow into China was slow and the actual investment showed no significant growth till 1991 . Beginning with a 25 percent growth in 1991, China has since attracted a greatly increased amount of FDI. A sharp increase (approximately 152 percent over the previous year) occurred in 1992 and an FDI inflow in 1992 (USD 11.007 billion) was just slightly lower than the total FDI (USD 12.103 billion) in the entire first decade (1979-1989). By 1998, this 1992 level was surpassed four times over (SSBPRC, 1988-1999). The country had been second only to USA as the major recipient of FDI from 1993 to 1997 and ranked in the third position in 1998 in the world. During the period 1992 to 1998 , China had hosted almost 10 percent 
of the total world FDI inflow in the world and absorbed over 28 percent of the total FDI inflow to developing countries and over 46 percent of total FDI inflow to Asian countries or regions. South East Asian countries or regions attracted about USD 480 billion FDI flows from 1992 to 1998. Approximately 50 percent of this went to China (UN, 1996-1999).

\section{Figure 1 \\ FDI Inflow to China (1979-1998)}

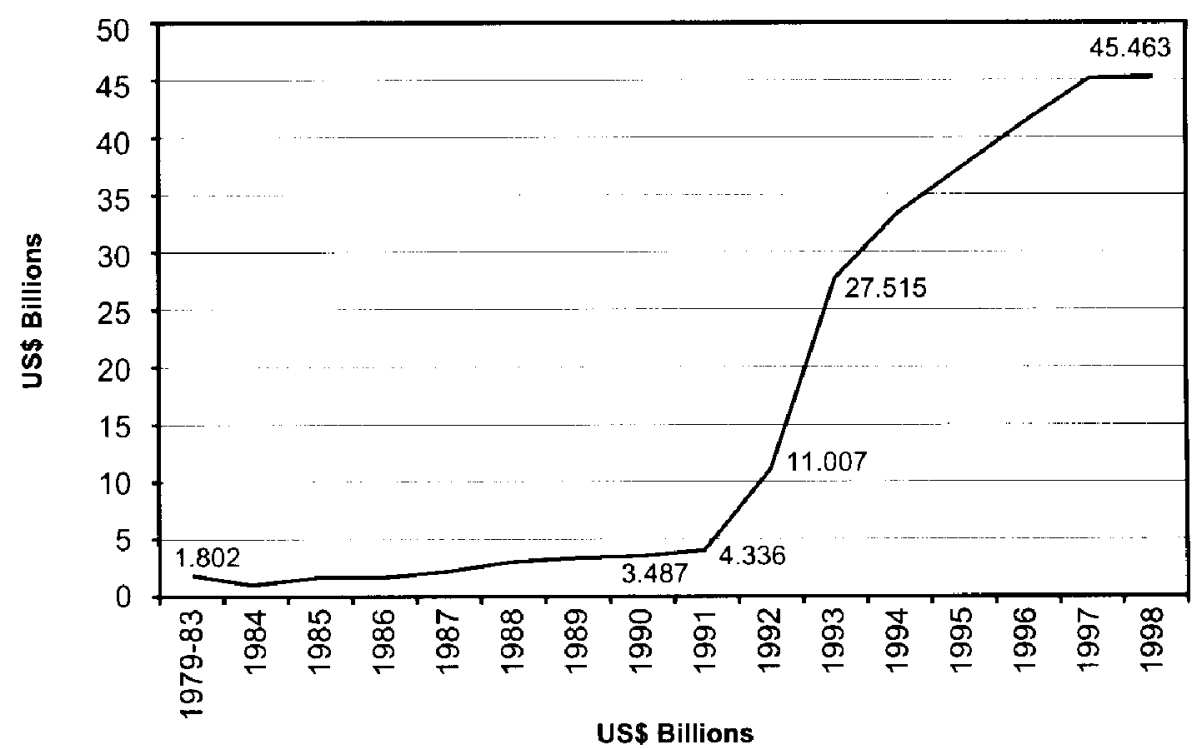

Source: Figures extracted from SSBPRC, 1988-1999

The popularity of foreign direct investment activities in China applies notably to the pharmaceutical industry. The Chinese pharmaceutical industry has become one of the first groups of industries that established enterprises using foreign investment. By the end of 1998, China had established over 1,500 pharmaceutical companies with foreign investment, including investment by the majority of large multinational pharmaceutical groups from North America, Western Europe and Asia. Foreign invested pharmaceutical companies were distributed across almost every part of China. They produced a wide range of products, including, for example, bulk pharmaceutical chemicals, preparations, diagnostic reagents, medical dressings, pharmaceutical machinery and health care products (CCPIE, 1995; NTDB, 1996; MIMS, 1998; SPGC, 1999). With foreign cooperation and the successful introduction of foreign investment, China's pharmaceutical industry has expanded at a very fast rate, with annual market growth posting an average double-digit growth for the past two decades. Analysts anticipate that China will be the world's largest pharmaceutical market by year 2020 and the world's leader of pharmaceutical manufacturing during the 2011 to 2050 period (Wang, 
1999). This study, by means of both qualitative and quantitative approaches, investigated the determining factors that affected international pharmaceutical firms' FDI into China and explored the relationships between the importance of determinant variables and the timing of FDI decisions by taking the year of 1992 as a cutting point.

While China formally permitted the participation of foreign investors in 1979, there were relatively little activity until 1991. The year 1992 became a turning point in China's political-legal and economic reforms. This followed the muchpublicised tour of the former leader, Deng Xiaoping, to the southern provinces of China early that year and his call for the acceleration of economic reform and the opening up of the economy to the outside world. The central government adjusted its economic policy in order to speed up economic reform and to further open the economy to foreign investment. The Chinese government announced the adoption of the 'socialism market economy' strategy and began to build a legal framework to standardize market operation. Regulations covering corporation law, bankruptcy law, individual income law, stock trading law, and some other commercial regulations have been passed since 1993. Other reform measures included changes to the tax system and permitting the conversion of Chinese currency. This created a favourable business environment and facilitated the functioning of market mechanism. In addition, privatization of state-owned enterprises (by selling the government share to the public) and lowering tariffs for imports have been important measures further liberalizing the Chinese economy. These measures promoted high economic growth and a favourable business environment for foreign investment into the country (Sun, 1998). The dramatic changes in Chinese politics and economic policies since 1992 appear to have had significant impact on international pharmaceutical firms' FDI into China. Therefore, firms whose FDI into China was prior to 1992 were classified as early entrants and those that started their FDIs since 1992 as late entrants. A comparison of FDI decision patterns between the Pre-1992 Period (early entrants) and the Post-1992 Period (late entrants) should provide a better understanding of FDI theories and practices in China.

\section{Literature Review}

The theories of foreign direct investment have traditionally emphasised market imperfection (Hymer, 1960), location specific advantage (Franko, 1971; Vernon, 1977), internalization theory (Buckley \& Casson, 1976) and transaction cost theory (Williamson, 1975, 1985; Buckley \& Casson, 1976; Caves, 1982; Anderson \& Gatignon, 1986). Dunning's (1988) "eclectic paradigm" denoted that a firm's FDI decision is influenced by three types of factors: ownership-specific factors of a firm, location-specific factors of a market and internalization advantages of integrating transactions within the firm. Taggart (1993) suggested that the three main divisions of FDI theory (three-division theory), via approaches based on domestic market imperfections, firm specific advantages and location specific advantages were 
generally more appropriate reasons for why multinational pharmaceutical firms invest abroad rather than in their home countries or regions. Location-specific advantages, including market size (Kueh, 1992; Tesai, 1994; Lardy, 1995; Wang \& Swain, 1995, 1997; Milner \& Pentecost, 1996; Broadman \& Sun, 1997; Park, 1997; Qu \& Green, 1997; Fittock \& Edwards, 1998; Sun, 1998; Wu, 1999; Yan, 2000), stage of economic development (Tesai, 1994; Zhang \& Yuk, 1998), openness of the economy (Singh \& Jun, 1995; Walder, 1996), political stability (Walder, 1996), host country's incentive policies (Zhang \& Yuk, 1998; Li \& Li, 1999) and labor cost considerations (Tesai, 1994; Wei \& Christodoulou, 1997; Li $\& \mathrm{Li}, 1999$ ) have recently attracted considerable research attention in explaining why FDI occurs in China. Li and Li (1999) clarified that foreign investors with new technology and new management skills were primarily attracted by China's huge potential domestic market and geared mainly towards long-term strategic considerations, whereas the foreign investors who made investments in laborintensive production geared towards export were mainly aiming for China's cheap labor costs. Zhang and Yuk (1998) asserted that FDI patterns in China are most likely to be determined by the location specific advantages such as large market size and low labor costs.

However, the existing literature does not address whether the timing of FDI has any significant impact on firms' FDI decisions into China, although China's economic system has been in a gradual transition process from the centrallyplanned economic system to what is termed socialism-market economic system in a 'learning-by-doing' process since 1979 (DFIMFTECPRC, 1995). This comprehensive (and complicated) experimental process has been accompanied by essential political/legal and economic environmental changes in China that might have influence on international investors' FDI decisions to enter China. In fact, FDI inflow into China has experienced two main distinctive patterns during the period of 1979-1998; that is, following a slow growth period from 1979 to 1991, FDI inflow has increased dramatically since China's former leader Deng Xiaoping's south China tour in 1992. In addition, the general strategic literature on the timing of entry has focused on the early mover advantages and disadvantages (Conner, 1991; Kalyanaram, Robinson, \& Urban, 1995; Vanderwerf \& Mahon, 1997; Makadok, 1998; Luo \& Peng, 1998; Song, Di Benedetto, \& Zhao, 1999) and the impact of timing of entry on firms' performance (Kerin, Varadarajan, \& Peterson, 1992; Shaver, Myles, Mitchell, \& Yeung, 1997; Lieberman \& Montgomery, 1998; Luo, 1998; Peng , Li \& Tse, 1999; Isobe, Makino, \& Montgomery, 2000). Therefore, a comparison between the impacts of the driving forces on the FDI decision making processes of early and late entrants should contribute to the understanding of the temporal fashion of FDI into China during the different periods.

Furthermore, the existing literature also remains controversial in relation to the variables of incentive policies, low labor cost and market size. A number of the empirical studies (Hartman, 1984; Boskin \& Gale, 1987; Slemrod, 1990) revealed that specific incentives such as lower tax have no major impact on FDI decisions. Wu (1999) also argued that large market size and low labor cost are not unique 
to China. India, for example, is also a large nation and cheap labor is accessible there, as in developing countries. Thus, the international pharmaceutical firms' FDI in the Chinese pharmaceutical manufacturing industry remains unexplained in the existing literature, although the international pharmaceutical groups have been actively pursuing and evaluating avenues of access to what could become the world's largest drug market. This study, therefore, aimed at overcoming the shortcomings of previous studies by taking an exploratory approach to investigate the determining factors that drove international pharmaceutical firms' foreign direct investment into China during the period of 1980-1998 and the impact of timing of FDI on firms' FDI decisions.

\section{Research Method}

\section{Population and Sample}

A total of 117 international-pharmaceutical-firm-invested pharmaceutical companies (IPFIPCs) in Mainland China were defined as the population for the research, based on four major sources: 1) the Catalogue of Chinese Pharmaceutical Enterprises with Foreign Investment (published by the China Centre for Pharmaceutical International Exchange (CCPIE, 1995), an agency of State Pharmaceutical Administration of China); 2) the Market Reports of National Trade Data Bank of the United States of America (NTDB, 1996); 3) MIMS Asia (MIMS, 1998); and 4) the report of Shanghai Pharmaceutical (Group) Corporation (SPGC, 1999). Pharmaceutical companies that had capital investment by non-pharmaceutical firms (for example, business trading companies and investment development firms) were not included in the research population. The key difference between the pharmaceutical and non-pharmaceutical firms is that the non-pharmaceutical firms do not have the technology advances in pharmaceutical research and product development as do the pharmaceutical firms, and these technology advances may have significant influences on foreign investors' FDI decisions. Within the population, ninety-nine firms ( $84.6 \%)$ chose a joint venture entry operation with a local Chinese partner as their entry mode for the Chinese market and the remaining firms (15.4\%) established 100 percent foreign-owned sole venture operations in China. The local Chinese partners were mainly state-owned Chinese pharmaceutical firms or government agencies.

Over 84 percent of IPFIPCs were located in east China's thirteen provinces and municipalities including Hainan, Guangdong, Fujian, Zhejiang, Shanghai, Jiangsu, Anhui, Shangdong, Hebei, Tianjin, Beijing, Liaoning and Hellongiiang. The east China region was the priority area for the Chinese government to initially practice the policy of opening to the outside world for foreign investment. China's five special economic zones (SEZs), fourteen coastal open cities and the Shanghai Pudong New Development Area are all located in this region, whose investment environment is relatively advantageous over China's middle and west areas. In August 1980, China created the four SEZs of Shenzhen, Zhuhai, Shantou and Xiamen in south east China's coastal area. In 1988, Hainan Province, the China's 
largest island province was defined as the fifth special economic zone. The SEZs are comprehensive experimental sites for China's economic restructuring and opening to the outside world. They also serve as a special channel for China to use foreign investment, to import advanced technology and enter international markets (DFIMFTECPRC, 1995). In April 1984, the Chinese Government defined a total of fourteen cities as coastal open cities including Tianjin, Shanghai, Dalian, Qinhuangdao, Yantai, Qingdao, Lianyungang, Nantong, Ningbo, Wenzhou, Fuzhou, Guangzhou, Zhanjiang and Beihai, In an effort to support these cities in bringing their advantages into full play (for example, existing industrial and technological bases, harbour transportation, scientific research and education, increasing international economic links and accelerating economic development) the Central Chinese Government has offered these cities policy preferences. These include the power to make decisions independently on foreign economic and trade activities, preferential treatment for foreign-funded enterprises and technical transformation of old enterprises. In investing in these cities, foreign investors can enjoy preferential treatment on taxation. For example, the income tax on productive enterprises with foreign investment is levied at a reduced rate of 24 percent and the income tax on foreign-funded enterprises undertaking projects encouraged by the State is levied at a reduced rate of 15 percent (DFIMFTECPRC, 1995). In June 1990 the Chinese Government approved a plan to authorize the municipality of Shanghai to develop and open the Pudong New Area and to exercise some policies in the area analogous to those applied in the SEZs. As the most economically developed areas of China, the east China region proves to be a decisive force in the national economy and social development of China (ECPRCY, 1999). As a result, a majority of foreign-funded businesses in China have been established in this region. Foreign-funded projects in mid-western China are relatively few. This also applies to the locations of international pharmaceutical firms' FDI in China. A total of 98 IPFIPCs that were distributed in the three major regions in east China and accounted for 83.76 percent of the population were defined as the sample size for this research. These IPFIPCs in the sample include twenty-nine in South East Region (SER), thirty-eight in Middle East Region (MER) and thirty-one in North East Region (NER). The SER comprise of Guangdong and Fujian provinces. The MER covers Shanghai municipality, Jiangsu, Anhui and Zhejiang provinces. The NER consists of Beijing and Tianjin municipalities, Liaoning, Shandong and Hebei provinces (CCPIE, 1995; NTDB, 1996; MIMS, 1998; SPGC, 1999).

\section{Data Collection}

A questionnaire was designed in both English and Chinese and was reviewed by two bilingual speakers. One reviewer was a graduate from a Chinese university in China with a major in English studies and had received an MBA degree from an Australian university. Another held an Australian master's degree in marketing. The questionnaire was also pre-tested by six respondents using four personal interviews, one mail questionnaire survey and one telephone survey. Of the six pretesting respondents, four had received MBA degrees from Australian universities 
and had worked for foreign invested companies in China for a number of years in senior management positions. Two of them had worked for IPFIPCs in China. The rest were senior managers of a large Chinese-US joint venture pharmaceutical company in China at the time the pre-testing took place.

The fieldwork began in early April 1999 and was conducted over a 3-month period. The data were collected, in the main, from personal interviews and complemented by mail questionnaire surveys. Personal interviews were conducted with senior executives of foreign business partners in IPFIPCs in China and the postal questionnaires were addressed to foreign senior executives in IPFIPCs in China. In line with the logic of John (1984), who argues for selecting knowledgeable informants, the choice of this rather exclusive respondent group is based on the belief that people in these sensitive positions are the most cognizant about global investment projects and the dynamics of the overall foreign entry decision process (Kim and Hwang, 1992; Chandprapalert, 2000). In total, 44 companies participated in this research and 82 percent of completed questionnaires were obtained through personal interviews. Of the 44 responding IPFIPCs, 43 firms provided useful data for the research question. These firms include 16 firms that were established in China before 1992, and 27 that have been set up since 1992. Amongst 16 early entrants, 10 IPFIPCs had investment by Asian firms mainly from Hong Kong, Taiwan and Japan. The remainder of the early entrants were mostly from USA and Western European countries. The western firms also comprised about 60 percent of the late entrants. About 62 percent of the firms in the sample invested less than USD20 million in China ${ }^{1}$. Over 81 percent of early-entrants committed to this smaller scale of investment and the same percentage applies to the proportion of late entrants who invested more than USD20 million in China. In the sample, three companies, including two in Guangdong and one in Jiangsu, were found to have ceased operations during the fieldwork. In addition, one company in Guangdong had the foreign partner's share sold to its Chinese partner before this survey was conducted. Therefore, the real sample size was reduced from an estimated 98 to 94 IPFIPCs, resulting in a 45.74 percent response rate.

\section{Data Analysis and Results}

Respondents were asked to describe why their parent firms made FDI decisions to invest in China. The responses were categorized in a similar way prescribed by Walsh, Wang, and Xin (1999), and Coffey and Atkinson (1996). That is, following the scanning of data a number of times, bulk groups of data sets were created, based on those with most appropriate meaning. Each bulk group of data set then was condensed into analyzable units by creating categories and each category was treated as an independent variable (factor) for statistical analysis. In total, ten categories were identified, including China's market size with great potential (for pharmaceutical products); rapid economic development and growth, China's opendoor policy, relatively stable political conditions, low cost of establishment of plant and facility, incentive policies, low labor cost in China, traditional contacts and linkages, similar culture and language, and continuation of previous business. 
The quantitative data analysis procedures were performed with SPSS (version 10) following data categorization. The descriptive analysis was carried out, first, to summarize the frequency percentages for each factor considered by foreign firms with respect to their FDI decision into China. Variables considered as important factors by firms were coded as ' 1 '; those not considered were coded as ' 2 '. The Figure 2 presents the descriptive results of the number of firms that considered each particular factor. It reveals the existence of four distinctive patterns. The primary concerns of the ten factors were strongly associated with China's political, economic, social and culture conditions. The first two most important factors, China's market size with great potential and rapid economic development and growth are connected with China's market and economic conditions and the second two most important factors, China's open-door policy and stable political conditions are related to the government's policy on business and economic activities. Of these, China's open-door policy seems to be more important than relatively stable political conditions to foreign investors' FDI decisions. Incentive policies provided by China tended to have a minor impact on the pharmaceutical firms' FDI decisions to invest in China. The remaining five factors, including low cost of establishment of plant and facility, low labor cost, traditional contacts and linkage, similar culture and language and continuation of previous business turned out to be insignificant in the context of international pharmaceutical firms' FDI into China. Each participating firm reported more than one factor that influenced its FDI decisions to invest in China. On average, the number of factors reported, per firm, was 2.88. The independent sample $t$-test suggested that there was no significant difference between early and late entrants $v i s-\dot{a}-v i s$ the average number of factors per firm reported (mean $=2.75$ for early entrants and mean $=2.96$ for late entrants, $p>.05, t=-0.5822$ ). This may suggest that the decisions of the international pharmaceutical firms' FDI into China were determined by a combination of factors.

The second level of analysis took consideration of the relatively small sample size used for this research. The Simple Logistic Regression (SLR) technique was used to investigate whether any associations existed between the importance of determinant factors and timing of FDI (Pre-1992 vs. Post-1992). The SLR is appropriate for a two-by-two table comparison, instead of using Pearson's chi-square test ${ }^{2}$. The Pre-1992 period (early entrants) was coded as ' 1 ' and the From-1992 period (late entrants) was coded as ' 2 '. The outcome of the SLR is shown in Table 1 and indicates that there was a significant positive relationship between the factor of China's open-door policy and the timing of FDI $(\beta=1.376$; $\mathrm{p}<0.05$ ). A significant negative relationship was identified between the factor of China's economic development \& growth and the timing of FDI $(\beta=-2.260$; $\mathrm{p}<0.01$ ); and a significant negative relationship was shown between the factor of relatively stable political conditions and timing of FDI $(\beta=-1.722 ; p<0.05)$. A positive beta $(\beta)$ indicates a positive relationship between the importance of factors and the timing of $F D I$ and means the factor was important in Pre-1992 (early entrants). Conversely, a negative beta $(\beta)$ indicates a negative relationship 
between the importance of factors and the timing of FDI and means the factor was important in From-1992 (late entrants). Thus, the results reveal that early entrants viewed China's open-door policy to be more important than did the late entrants. On the other hand, the late entrants were more likely to consider China's economic development and growth and relatively stable political conditions as important positive factors to their FDI decisions.

Figure 2

Exploratory Variables by Frequency of Participating Firms $(\mathrm{N}=43)$

Variables (Factors)

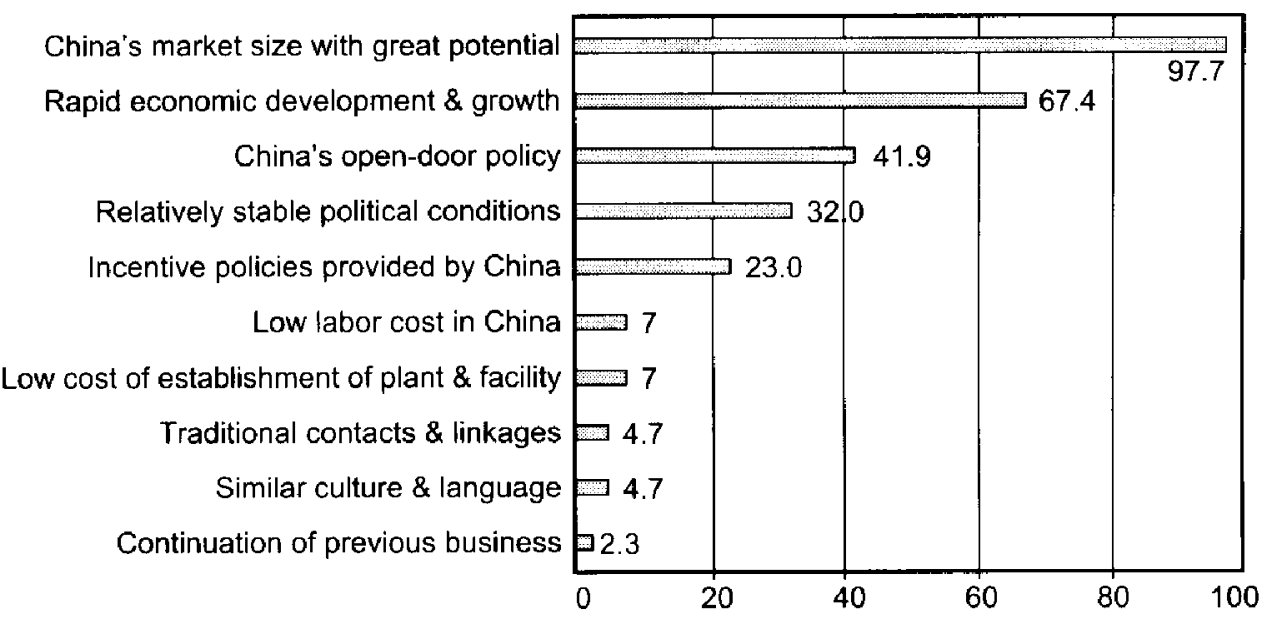

Table 1

Simple Logistic Regression by Exploratory Variables Dependent Variable: Timing of FDI (Early Entrants vs. Late Entrants)

\begin{tabular}{lrl}
\hline \multicolumn{1}{c}{ Variables } & $\beta$ & Sig. \\
\hline China's market size with great potential & 6.7162 & .8546 \\
Rapid economic development and growth & -2.2600 & $.0025^{* *}$ \\
China's open-door policy & 1.3758 & $.0390^{*}$ \\
Relatively stable political conditions & -1.7222 & $.0426^{*}$ \\
Low cost of establishment of plant \& facility & -7.7970 & .8232 \\
Incentive policies provided by China & 1.2384 & .0980 \\
Low labor costs in China & 1.3120 & .3011 \\
Traditional contacts \& linkage & .5500 & .7046 \\
Similar culture \& language & .5500 & .7046 \\
Continuation of previous business & -6.7162 & .8546 \\
\hline
\end{tabular}

$* \mathrm{p}<.05 ; * * \mathrm{p}<.01 ; * * * \mathrm{p}<.001$

A positive beta $\beta$ means important in Pre- 1992 period for early entrants

A negative beta $\beta$ means important in From-1992 period for late entrants 


\section{Conclusion and Discussion}

The purpose of this research was to examine the determinants of international pharmaceutical firms' FDI into China during the period from 1980 to 1998. It differentiated itself from similar studies on FDI into China by investigating the determinants of international pharmaceutical firms' FDI into the Chinese pharmaceutical industry and the possible changes in importance of determining factors through time. As such, the study advances the understanding of the industry specific nature of FDI and the temporal fashion of FDI into China during the different periods. The research results suggest that international pharmaceutical firms'FDI into China was determined predominantly by China's location-specific factors. This finding partially supports Dunning's (1988) eclectic paradigm and Taggart's (1973) three-division theory on multinational pharmaceutical firms' FDI activities. However, it was consistent with most recent studies on multinational firms' decisions to invest in China. The research results reveal that four factors, namely China's market size with its great potential, rapideconomic development and growth, China's open door policy and relatively stable political conditions have been the major motivations in attracting international pharmaceutical firms' direct investment into the Chinese pharmaceutical manufacturing industry during the period from 1980 to 1998. Incentive policies provided by China had no major impact on firms' FDI decisions. The low labor cost and social-cultural related factors appeared to be insignificant to international pharmaceutical firms' FDI decision into China. Steady GDP growth, increase of income per capita, consistent increase of per capita annual expenditure on medicine and medical service, together with over 1.2 billion people make the factor of China's market size with its great potential the most important motivation among the four major factors.

The importance of the other three important factors depends on the timing of FDI into China. China's open-door policy played the second most important role in encouraging international investment particularly during the early stage of China's economic reform and socialism market development. The promulgation of the Law of the People's Republic of China on Joint Ventures Using Chinese and Foreign Investment in July 1979 was a momentous event in China's opening up of the economy. The gradual implementation of the open door policy represented a breakthrough from the past in China's economic development strategy. The open door policy was a strong signal to the outside world and indicated China's intention to break out of its international isolation and become aggressively involved in the world economic activities after three decades of isolation and central planning of the economic system. The open door policy brought new opportunities for foreign investors who intended to develop business in the Chinese market.

The rapid economic development and growth, combined with the relatively stable political conditions in China, has had significant impact on international investors' decisions to make direct investment in the country particularly since 1992. The speeches of China's former leader, Deng Xiaoping, published in 1992, have accelerated the processes of the Chinese economic reform and opening up 
the economy for foreign investment, which have had positive impact on economic development and political conditions in the country, in turn contributing to the late entrants' FDI decision to invest in China.

Economically, China has achieved an average of double-digit growth in GDP during the period 1979-1998 and the growth rate was higher during the From1992 period (10.7\%) than that in the Pre-1992 period (9.1\%). More importantly, since 1992 the country has achieved economic stability and sustained growth with controlled inflation, this having followed a number of dramatic fluctuations in GDP rates during the Pre- 1992 period of its economic reform and development (SSBPRC, 1999). The strong, balanced, economic growth and control of inflation, rather than the attainment of rapid growth at all costs, remain the government's prime objectives (Hatheway, 1998). The country claimed significant success in macroeconomic management with controlled consumer and retail price inflations at $2.8 \%$ and $0.8 \%$ respectively, in 1997 . The central Chinese Government has also successively established and opened a series of 'coastal open areas' and has introduced the policy of 'opening cities on rivers and borders' for foreign investments since 1992. Consequently, 6 port cities on the Yangtze River, as well as 13 inland border cities and capitals of provinces and autonomous regions have been opened and offered preferential policies. These include tax reduction similar to those for coastal open cities and/or special economic zones defined and created by the Chinese Central Government before 1992 to serve as a special channel for China to use foreign investment and to import advanced technology and enter international markets (DFIMFTECPRC, 1995; Li \& Li, 1999). Therefore, the rapid economic development and growth, together with the central Chinese government's stronger commitment to the economic reform, have created a more promising market with greater potential and a more favourable investment environment to better facilitate FDI into the country since 1992.

A number of recent studies on timing of market entry revealed that the early entrants may have the advantages in market growth (Kalyanaram, et al., 1995; Vanderwerf \& Mahon, 1997; Makadok, 1998; Song, et al., 1999), pricing strategies (Makadok, 1998), technological leadership, creation of buyer switching costs and positive economic benefits (Lieberman \& Montgomery, 1998) and development of valuable and non-substitutable resources (Conner, 1991; Makadok, 1998). In the context of FDl in China, the early movers may outperform the late entrants in market growth and asset efficiency and enjoy the benefit from more pre-emptive market opportunities and business potentials than they would in the home market. In contrast, the early entrants encountered greater risks than the late entrants did in the start-up phase of international expansion. China is an economy in the process of transformation, which could present daunting challenges to the unwary investors (Luo, 1998). Foreign investors, in general, were concerned about China's political instability, especially during the Pre-1992 period when the 1989 Tiananmen Square incident occurred after a number of failures in the transformation of Chinese leadership. Many foreign investors were unsure of the direction the country was taking. Most complaints from foreign investors 
in China in the early stage of economic reform and development related to the uncertainty and opacity of local laws, rules and government policies on FDI (National Council, 1991). The political and social uncertainties arising in the transitional stage often reinforce variations in contextual conditions (Peng \& Heath, 1996). In addition, far-reaching changes in industry and market structures in the early stage of structural transformation caused substantial variance in the investment environment that could lead to the instability of foreign invested firms in China (Luo, 1995). The superiority of the advantages to early investor's accrued at the expense of high operational risk in the local environment (Luo, 1998). Therefore, in addition to the possible advantages the early investors might be able to take (as revealed in previous studies), there are a number of possible factors that contributed to the early entrants' decisions on the timing of entry into the Chinese market by the international pharmaceutical firms. First, approximately two-thirds of the early investors were from Hong Kong, Taiwan and Japan, who might have a better understanding of the China's overall investment environment and the skills to cope with the uncertainty in the environment. Second, over fourfifths of the early entrants committed a smaller scale of capital investment in the China ventures. Furthermore, the international pharmaceutical firms introduced conventional drug technology, rather than the latest innovative technology, to the Chinese market. This was achieved by transferring the manufactured conventional drugs from the operations in their home countries to the China ventures, then marketing the drugs into the Chinese market. These factors could be viewed as a first step to test the market in the early stage of FDI activities in China, which brings into line with Williamson's (1985) transaction cost theory suggesting that when uncertainty is high, the firm should minimise its commitment to the environment. Third, the large majority of international pharmaceutical firms formed joint ventures with local Chinese partners. A competent local Chinese partner can assist the ventures in reducing the risks associated with the uncertainty by using their country-specific knowledge. This applies even more so for early entrants since they had a better chance to choose a more competent partner while more alternative partners were still available to them in the early stage of FDI activities. Finally, the early investors concentrated their investments in SEZs or open cities. As Luo (1998) pointed out, ventures located in those open areas are able to foster risk reduction in China. The four attributes deal with investors' capability (local environment know-how) and investment strategies (partner selection, venture location selection within China and scale of investment). This may suggest that, other things being equal, a firm's early entry decision into a politically uncertain international market like China also depends on what the firm can do (capability) and how to do it (investment strategies).

Since 1992, a collective leadership rather than a single, predominant leader has governed China. Political stability and economic development and reform have been priority objectives of the central Chinese government. Also since 1992, an upsurge of foreign investment swept across the country and the introduction of foreign investment underwent a new, substantial development, both in breadth 
and depth. Since then, a legal framework governing foreign investment activities and a market-oriented system has been established. Most notably, China has made significant progress in implementing intellectual property rights regulations, education and enforcement, as international pharmaceutical firms were sensitive to, and concerned about the weak intellectual property rights protection. After a few years of negotiation between China and the United States of America, the two countries signed a bilateral agreement on the protection of intellectual property rights in February 1995 and the agreement in June 1996 on procedures for ensuring its effective implementation. The economic transition proceeds and the Chinese markets are becoming more and more integrated with the global economy; and the contextual risks and uncertainties have been therefore gradually diminishing over time. Overall, the political environment for international investors has been improved significantly. Outstanding economic performance has provided the late entrants with a relatively stable investment environment for their long-term business development in China. These improvements may also explain in large part why China was more attractive than other nations that also have low labor costs and potential large market size advantages.

This study also demonstrated that the incentives provided by the Chinese government would most likely be treated as an additional benefit by most international pharmaceutical firms, rather than a decisive factor on their FDI decisions to China. This finding supports previous studies primarily based on FDI in the USA (Hartman, 1984; Boskin \& Gale, 1987; Slemrod, 1990), although contrasts findings of recent studies based on FDI in China (Zhang \& Yuk, 1998; Li $\& \mathrm{Li}, 1999$ ). This may be because the pharmaceutical industry is more technologybased, rather than a labor-intensive industry. International pharmaceutical firms who invested their capital and technology into China were primarily aiming to access China's potential huge market for their products. Usually, export-oriented FDI have invested mainly in labor-intensive industries. Therefore, the incentives may be significant for export oriented investments in labor-intensive industries in China. For similar reasons, cheap labor, low establishment costs and social cultural related factors would not have significant effects on international pharmaceutical firms' FDI decision into the Chinese pharmaceutical manufacturing industry. This finding supports $\mathrm{Li}$ and Li's (1999) clarification about the impact of China's low cost of labor on foreign firms" decision to invest in the country.

\section{Limitations and Future Research Directions}

There are three main limitations in this research. This research suggests that the timing of FDI had significant impacts on FDI determinants. The changes in investment environments and other conditions in China are continuing, as the political/legal and economic reforms in China are still on unfolding. This study was conducted in a particular time period and only gives insights into the situation at that moment in time (1980 to 1998). Second, most of the pharmaceutical companies with foreign investment in China are firms that have investment by 
international non-pharmaceutical firms (CCPIE, 1995; MIMS, 1998). Therefore, further research into FDI of international non-pharmaceutical firms would be expedient and meaningful. In addition, a comparison of determinants between pharmaceutical and non-pharmaceutical firms FDI in the pharmaceutical industry would further add to the understanding of how FDIs operate. Finally, future research studies may also extend to other industries rather than just the pharmaceutical industry, as international investors have also been actively engaging in other industries in China.

\section{Reference}

Anderson, E., \& Gatignon, H. (1986). Modes of foreign entry: A transaction cost analysis and propositions. Journal of International Business Studies, 17(3), 1-26.

Boskin, M.J., \& Gale, W.G. (1987). New results on the effects of tax policy on the international location of investment. In M. Feldstein (Ed.) The effects of taxation on capital accumulation. Chicago: University of Chicago Press.

Broadman, H.G., \& Sun, X. (1997). The Distribution of foreign direct investment in China. The World Economy, 20(3), 339-362.

Buckley, P.J., \& Casson, M. (1976). The future of the multinational enterprise. London: Macmillan.

Caves, R.E. (1982). Multinational enterprises and economic analysis. New York: Cambridge University Press.

CCPIE (China Centre for Pharmaceutical International Exchange). (1995). Catalogue of Chinese enterprises with foreign investment. Beijing: CCPIE.

Chandprapalert, A. (2000). The determinants of U.S. direct investment in Thailand: A survey on managerial perspectives. Multinational Business Review, 8(2), 82-88.

Christensen, R. (1997). Log-linear models and logistic regression, (2nd ed.). New York: Springer.

Coffey, A., \& Atkinson, P. (1996). Making sense of qualitative data: Complementary research strategies. Thousand Oaks: Sage Publications.

Conner, K. (1991). A historical comparison of resource-based theory and five schools of thought within industrial organization economics: Do we have a new theory of the firm? Journal of Management, 17, 121-154.

DFIMFTECPRC (Department of Foreign Investment Ministry of Foreign Trade and Economic Co-operation People's Republic of China). (1995). The China investment guide, 5th ed. Hong Kong: CITIC Publishing House. 
Dunning, J.H.(1988). The eclectic paradigm of international production: A restatement and some possible extensions. Journal of International Business Studies, 19(1), 1-31.

ECPRCY (Editorial Committee of People's Republic of China Yearbook). (1999). People's Republic of China yearbook. Beijing: Xinhua News Agency.

Fittock, C.S., \& Edwards, W.R. (1998). The determinants of Australian direct investment in China. Journal of Asian Business, 14(3), 41-51.

Francis, G. (1999). Introduction to SPSS for windows, version 7.5, 8.0 - with notes for studentware, (2nd ed.). Sydney: Prentice Hall.

Franko, L.G. (1971). Joint venture survival in multinational corporations. New York: Praeger Publisher.

Hartman, D.G. (1984). Tax Policy and Foreign Direct Investment in the United States. National Tax Journal, 37, 475-88.

Hatheway, L. (1998). China: Political transition, gradual reform, coping with slower Growth. New Horizon Economies, (1st Quarter), 30-31.

Hymer, S. (1960). The international operations of national firms: A study of direct foreign investment. PhD Dissertation. Massachusetts: MIT Press.

Isobe, T., Makino, S., \& Montgomery, D.B. (2000). Resource commitment, entry timing, and market performance of foreign direct investment in emerging economies: The case of Japanese international joint ventures in China. Academy of Management Journal, 43(3), 468-484.

John, G. (1984). An empirical investigation of some antecedents of opportunism in a marketing channel. Journal of Marketing Research 12(3), 278-289.

Kalyanaram, G., Robinson, W., \& Urban, G. (1995). Order of market entry: Established empirical generalizations, emerging empirical generalizations, and future research. Marketing Science, 14, 212-221.

Kerin, R.A., Varadarajan, P.R., \& Peterson, R.A. (1992). First-mover advantage: A synthesis, conceptual framework, and research propositions. Journal of Marketing. $5 \underline{6}, 33-52$.

Kim, W.C., \& Hwang, P. (1992). Global strategy and multinationals" entry mode choice. Journal of International Business Studies 23(1), 29-53.

Kueh, Y.Y. (1992). Foreign investment and economic change in China. China Quarterly, $131,637-689$. 
Lardy, N.R. (1995). The role of foreign trade and investment in China's economic transformation. China Quarterly, 144, 1065-1082.

Li, F., \& Li, J. (1999). Foreign investment in China. Houndmills: Macmillan Press Ltd.

Lieberman, M., \& Montgomery, D. (1998). First mover (dis)advantage: Retrospective and link with the resource-based view. Strategic Management Journal, 19, 1111-1125.

Luo, Y. (1995). Business strategy, market structure, and performance of international joint ventures: The case of joint ventures in China. Management International Review, 35, $241-264$.

Luo, Y. (1998). Timing of investment and international expansion. Journal of International Business Studies, 29(2), 391-407.

Luo, Y., \& Peng, M.W. (1998). First mover advantages in investing in transitional economies. Thunderbird International Business Review, 40(2), 141-163.

Makadok, R. (1998). Can first-mover and early-mover advantages be sustained in an industry with low barriers to entry/imitation? Strategic Management Journal, 19, 683-700.

Milner, C., \& Pentecost, E. (1996). Location advantages and US foreign direct investment in UK manufacturing. Applied Economics, 28(5), 605-616.

MIMS Asia. (1998). China medicines and chemical reagents booklet: Manufacturers, distributors, representative offices. Hong Kong: MIMS Asia.

National Council for US-China Trade. (1991). Special reports on US investment in China. Washington, DC: Department of Commerce.

NTDB (National Trade Date Bank). (1996). Market report. National Trade Data Bank of United States of America.

Park, J.D. (1997). The special economic zones of China and their impact on its economic development. Westport: Praeger.

Peng, M.W., \& Heath, P.S. (1996). The growth of the firm in planned economies in transition: Institutions, organizations, and strategic choice. Academy of Management Review, 21, 492-528.

Peng, M.W., Li, S., \& Tse, D.K. (1999). The impact of order and mode of market entry on profitability and market share. Journal of International Business Studies, 27(1), 1-26.

Qu, T., \& Green, M.B. (1997). Chinese foreign direct investment: a subnational perspective on location. Aldershot: Ashgate. 
Shaver, J.M., Mitchell, W., \& Yeung, B. (1997). The effect of own-firm and other firm experience on foreign direct investment survival in the United States. Strategic Management Journal, 18(2), 325-342.

Singh, H., \& Jun, W.K. (1995). Some new evidence on determinants of foreign direct investment in developing countries. Policy Research Working Paper, no. 1531.

Slemrod, J. (1990). Tax effects on foreign direct investment in the United States: Evidence from a cross-country comparison. In A. Razin, \& J. Slemrod (Eds.) Taxation in the global economy. Chicago: University of Chicago Press.

Song, X., Di Benedetto, M., \& Zhao, Y. (1999). Pioneering advantages in manufacturing and service industries: Empirical evidence from nine countries. Strategic Management Journal, 20, 811-835.

SPGC (Shanghai Pharmaceutical Group Corporation). (1999). Shanghai pharmaceutical group corporation (report). Shanghai: SPGC.

SSBPRC (State Statistic Bureau of People's Republic of China). (1999). China statistical yearbook. Beijing: China Statistical Publishing House. (and previous issues 1988 - 1998) (in both Chinese and English).

Sun, H. (1998). Foreign investment and economic development in China, 1979-1996. Aldershot: Ashgate.

Tabachnick, B.G., \& Fidell, L.S. (1996). Using multivariate statistics, $\left(3^{\text {rd }}\right.$ ed.). New York: HarperCollinsCollegePublishers.

Taggart, J. (1993). The world pharmaceutical industry. London: Routledge.

Tesai, P.L. (1994). Determinants of foreign director investment and its impact on economic growth. Journal of Economic Development, 19(1), 137-163.

UN (United Nations). (1999). World investment report: Foreign direct investment. New York: United Nations. (and previous issues 1996-1998).

Vanderwerf, P., \& Mahon, J.F. (1997). Meta-analysis of the impact of research methods on findings of first-mover advantages. Management Science, 43, 1510-1519.

Vernon, R. (1977). Storm over the multinationals. Cambridge: Harvard University Press.

Walder, P. (1996). China's transitional economy. England: Oxford University Press.

Walsh, P., Wang, E.P., \& Xin, R.K. (1999). Same bed, different dreams: Working relationships in Sino-American joint ventures. Journal of World Business, 34, 6970 . 
Wang, Y.F. (1999). China meets the medicine market: the addition of a market economy in China is bringing new opportunities and challenges for its pharmaceutical industry. Chemistry and Industry, 12, (June), 462-467.

Wang, Z., \& Swain, N.J. (1995). The determinants of foreign direct investment in transforming economies empirical evidence from Hungary and China. Weltwirtschaftliches Archiv, 131(2), 359-382.

Wang, Z., \& Swain, N.J. (1997). Determinants of inflow of foreign direct investment in Hungary and China: Time-series approach. Journal of International Development, 9(5), 695-726.

Wei, H.C.\& Christodoulou, C. (1997). An examination of strategic foreign direct investment decision process: The case of Taiwanese manufacturing SMEs. Management Decision, $\underline{35(8)}, 619-630$.

Williamson, O.E. (1975). Markets and hierarchies. New York: The Free Press.

Williamson, O.E. (1985). The economic institutions of capitalism. New York: The Free Press.

Wu, Y. (1999). FDI and economic growth: an introduction. In Y. Wu (Ed.) Foreign direct investment and economic growth in China. Cheltenham: Edward Elgar.

Yan, Y. (2000). International joint ventures in China. New York: Macmillan.

Zhang, X., \& Yuk, H.P. (1998). Determinants of Hong Kong manufacturing investment in China: A survey. Marketing Intelligence \& Planning, 16(4), 260-267.

\section{Footnote}

1. A USD20 million investment is usually regarded as a rather small scale of investment for international pharmaceutical firms.

2. Pearson's chi-square test is only appropriate if there is sufficient data (Francis, 1999). Pearson's chi-square is equivalent to the simple logistic regression which uses the pooled estimate of the standard error (Christensen, 1997: 27). Logistic regression is relatively free of restrictions, with the capacity to analyse a mix of all types of predictors (continuous, discrete and dichotomous) the variety and complexity of data sets that can be analysed is almost unlimited (Tabachnick \& Fidell, 1996: 578). 
Jiang Fuming is a researcher and lecturer in International Business in the School of Business \& Information Management at The Australian National University. $\mathrm{He}$ received his Ph.D. in International Business/Strategic Management from The Australian Graduate School of Entrepreneurship at Swinburne University, Australia. His research interests include internationalization strategies of Chinese firms and foreign direct investment strategies of multinational corporations in China and Australia. 
Vol. 22, No. 1 